\title{
Multi-Band Antenna with Three Folded Monopoles for Mobile Communication Systems
}

\author{
Ahmad El Sayed Ahmad ${ }^{*}$ (), Alaa Choumane ${ }^{2}{ }^{\mathbb{C}}$, Jean-Marie Floc'h ${ }^{3}$, Philippe Morgand ${ }^{4}$ \\ ${ }^{1}$ Faculty of Sciences, Lebanese University, Tripoli, Lebanon \\ ${ }^{2}$ Faculty of Public Health, Lebanese University, Zahle, Lebanon \\ ${ }^{3}$ IETR, INSA Rennes, Rennes, France \\ ${ }^{4}$ Thales Communication, Colombes, France \\ Email: ^Elsayed.ahmad84@gmail.com
}

How to cite this paper: El Sayed Ahmad, A., Choumane, A., Floc'h, J.-M. and Morgand, P. (2020) Multi-Band Antenna with Three Folded Monopoles for Mobile Communication Systems. Wireless Engineering and Technology, 11, 23-29. https://doi.org/10.4236/wet.2020.113003

Received: June 13, 2020

Accepted: July 13, 2020

Published: July 16, 2020

Copyright $\odot 2020$ by author(s) and Scientific Research Publishing Inc. This work is licensed under the Creative Commons Attribution International License (CC BY 4.0).

http://creativecommons.org/licenses/by/4.0/

\section{(c) (i) Open Access}

\begin{abstract}
This paper presents the design and the experimental characterization of a new multi-band antenna consisting of three folded monopoles dedicated to mobile communication systems. The originality of this paper is to get the PMR (Professional or Private Mobile Radio) band with the GSM (Global System for Mobile Communications), DCS (Digital Cellular System) and UMTS (Universal Mobile Telecommunications System) bands. The main lobe of the antenna radiates in the zenith direction with a linear polarization over all bands. It is interesting to design the proposed antenna in order to obtain better performances in terms of directive radiation pattern (especially in the PMR band) in comparison with the already existing antenna systems in the wireless market for similar purposes. The prototype was studied with the software CST-MWS (Micro wave studio 2012). The antenna has been designed and successfully measured.
\end{abstract}

\section{Keywords}

Multi-Band Antenna, Folded Monopole, Directive Radiation Pattern

\section{Introduction}

Modern and future wireless systems are placing greater demands on antenna designs. Many systems now operate in two or more frequency bands, requiring dual or triple band operation of fundamentally narrow band antennas [1]. These include satellite navigation systems, cellular systems, wireless LAN and a combination of these systems. One of the most popular antennas employed in mobile communication systems is the monopole antenna and its family. The monopole 
antennas are convenient to match to $50 \mathrm{ohms}$, and are unbalanced. This eliminates the need for a balun, which may have a limited bandwidth. The simplest member of the family is the quarter wave monopole above a prefect ground plane. The impedance bandwidth achievable for the quarter wave monopole antenna is dependent on the radius of the cylindrical stub, and increases with increased radius. This is true up to a point where the stepped radius from the feed probe to the cylindrical element becomes abrupt. The radiation performance is also shown to be acceptable over a wide range of frequency. Investigations on planar monopoles of different geometrical shapes, such as the circular, triangular, rectangular and elliptical have since been conducted [2] [3].

This paper describes the design and development of antenna able to cover a wide frequency bandwidth for use in detection system placed on the board in vehicle. To achieve this detection, one antenna system is needed, both covering the PMR, GSM, DCS and UMTS bands, while presenting good mechanical characteristics. This paper describes the directive antenna developed for the receiving part. In [4] [5], they have worked on the same application, but the antennas designed do not work in the PMR band. The originality of this paper (compared to [4] [5]) is to get the PMR band in addition to the GSM, DCS and UMTS bands.

\section{Description of Antenna}

One way to obtain a dual band resonant structure is to have two paths with different lengths so that each one of them corresponds to about a quarter of the wavelength at the resonant frequency. It is well known that a monopole element placed over a ground plane (taking into account the method of images) forms a half-wavelength resonator (Hertz dipole). In our case, the basic element consists in a folded dipole associated with a limited ground plane [4]. This limitation of the ground allows obtaining large bandwidths, acting as a load when the last part of the dipole is widened [6]. The goal is to have three monopoles with lengths that correspond to about a quarter of the free-space wavelength at $400 \mathrm{MHz}, 900$ $\mathrm{MHz}$ and $2 \mathrm{GHz}$ respectively. However, in order to miniaturize the antenna, the monopoles need to be placed in a way that they occupy the minimum possible area. For this reason, a space-filling approach was employed. Then to achieve a directive radiation pattern, this structure is placed above a larger ground plane used as a reflector [7]. Afterwards the whole structure is modeled and simulated using a CST-MWS, including the rigid coaxial cable. The height between the upper and the lower ground plane is then adjusted to optimize the bandwidths while conserving a relatively low profile.

In terms of performances, the antenna must be directive at the axis with a linear polarization. As for the gain, it must be higher than $3 \mathrm{~dB}$. The reflection coefficient must be less than $-6 \mathrm{~dB}$ over all bands.

The topology developed is presented on Figure 1. The lower ground plane used is a 50 by $50 \mathrm{~cm}$ one, and the overall height represents $4 \mathrm{~cm}$. 


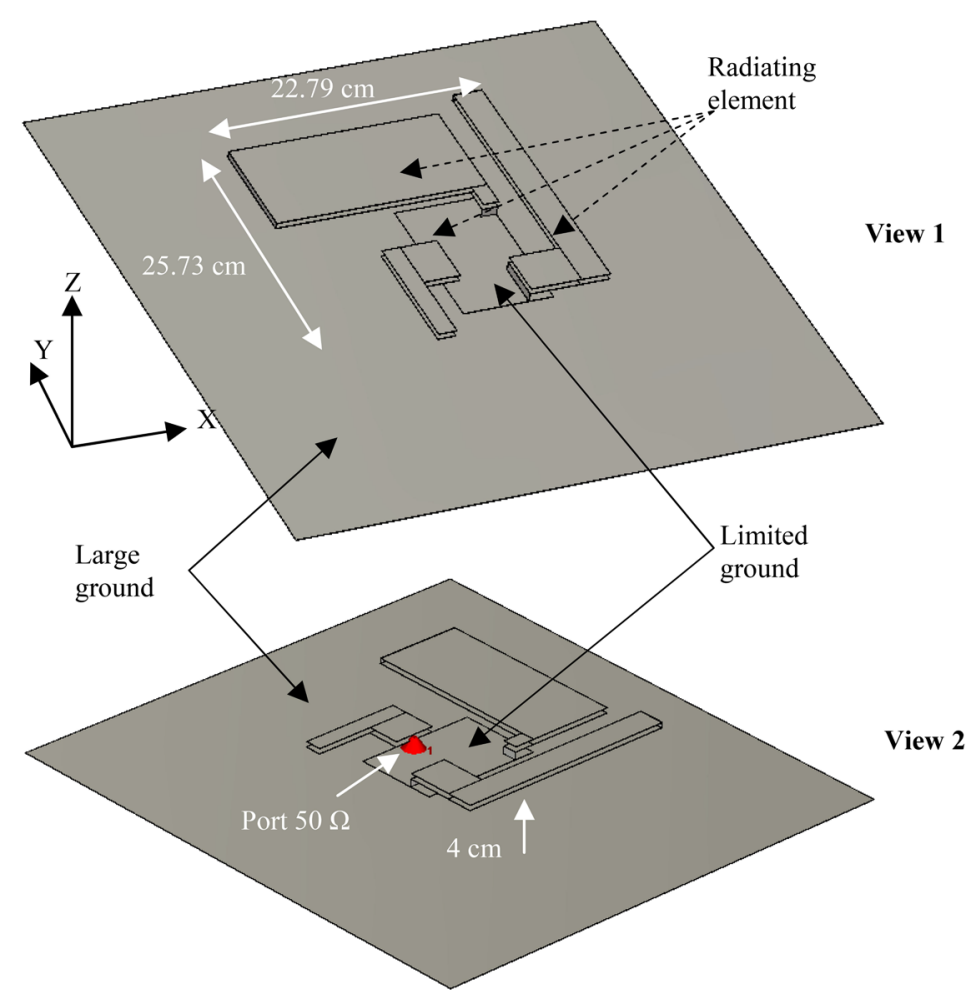

Figure 1. The proposed antenna.

\section{Numerical Validation}

As can been seen in Figure 2, the bandwidth $\left(\mathrm{S}_{11}<-6 \mathrm{~dB}\right)$ of the PMR band is $50 \mathrm{MHz}(380-430) \mathrm{MHz}$, at $900 \mathrm{MHz}$ it is $280 \mathrm{MHz}(810-1090) \mathrm{MHz}$, whereas at $2000 \mathrm{MHz}$ it is $1410 \mathrm{MHz}(1340-2750) \mathrm{MHz}$. The four operation bands provide not only large enough bandwidth to cover the applications operating within these frequency regimes, but also a sufficient frequency margin in case of detuning (i.e., realization). Particularly, the upper frequency band has a bandwidth that is much wider than the one of a classical monopole and this is due to the folded dipole associated with a limited ground plane.

The $3 \mathrm{D}$ radiation pattern is plotted on Figure 3. This numerical validation shows that the radiation pattern is successfully synthesized. In terms of levels, the simulated directivity at the axis higher than $3 \mathrm{~dB}$ over all bands satisfies the specifications in this direction.

\section{Measurement}

The prototype antenna is manufactured as can be seen in Figure 4. For the realization of the antenna, we use sheets of brass and Foam. We cut the foam in order to obtain the good heights for the different parts of the antenna. We glue after the cuts and the folding sheets of brass with the foams on the ground plane.

The measurements were achieved in the laboratory by using a Rohde \& Schwarz ZVL network analyzer for the reflection coefficient and our near field anechoic chamber (Stargate 32 by SATIMO) for the radiation measurements. 


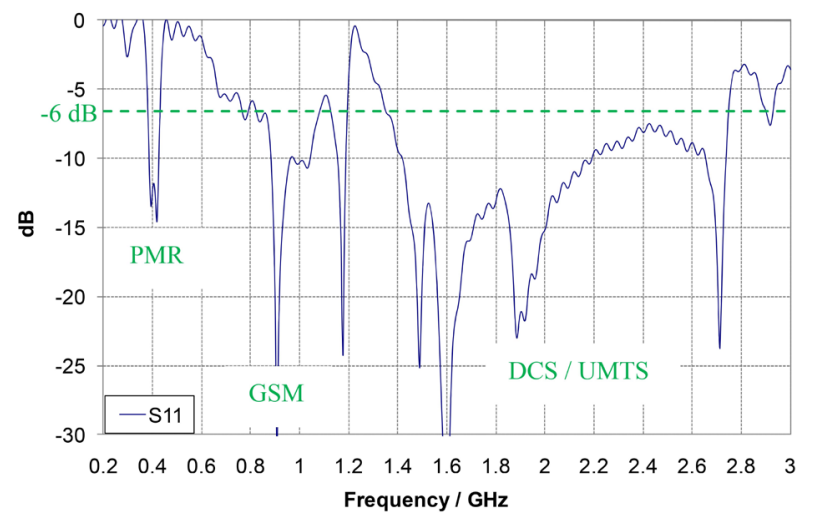

Figure 2. Simulated $S_{11}$ of the prototype antenna.
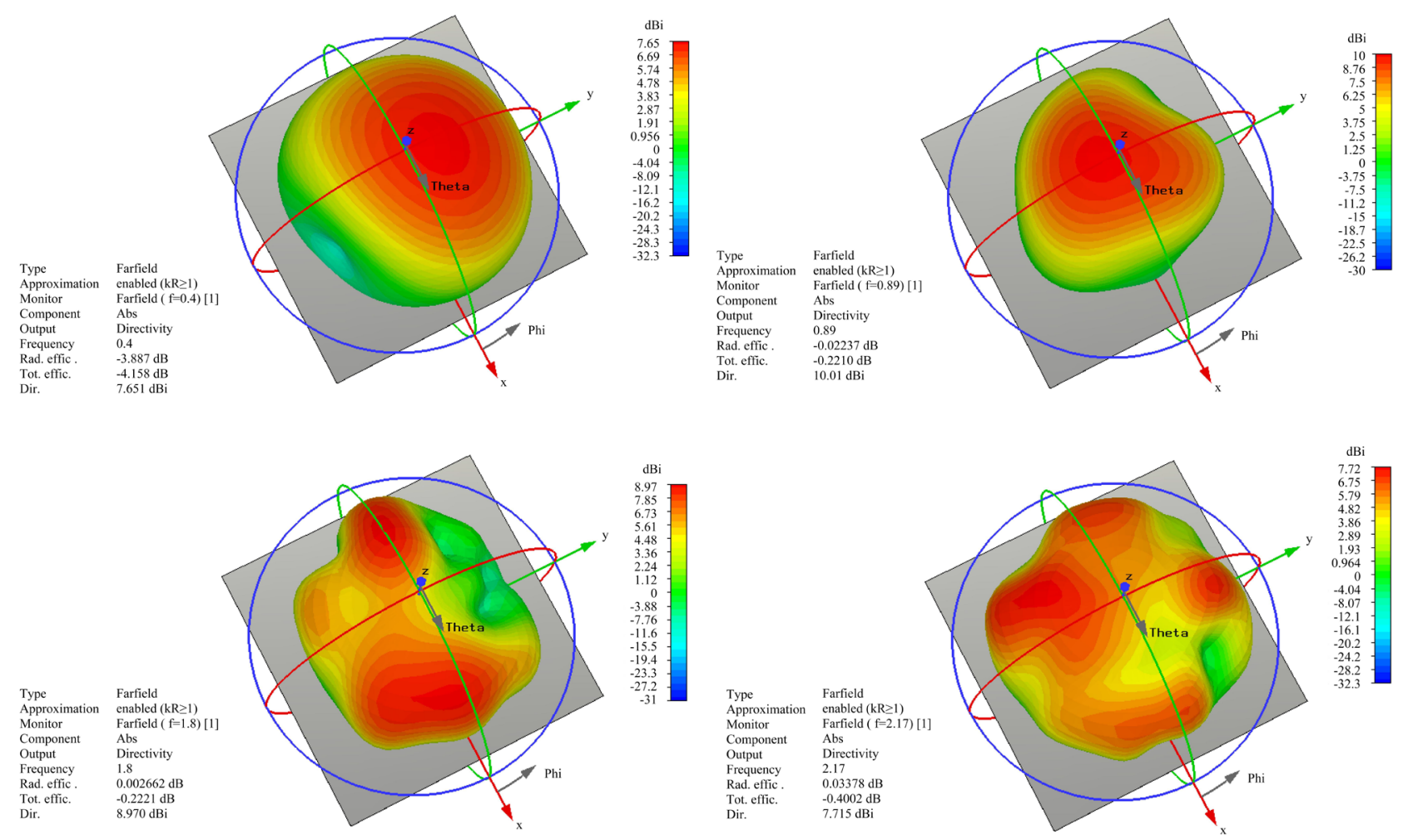

Figure 3. The 3D simuation radiation pattern (directivity) at four frequencies (400 MHz, $890 \mathrm{MHz}, 1800 \mathrm{MHz}$ and $2170 \mathrm{MHz}$ ).

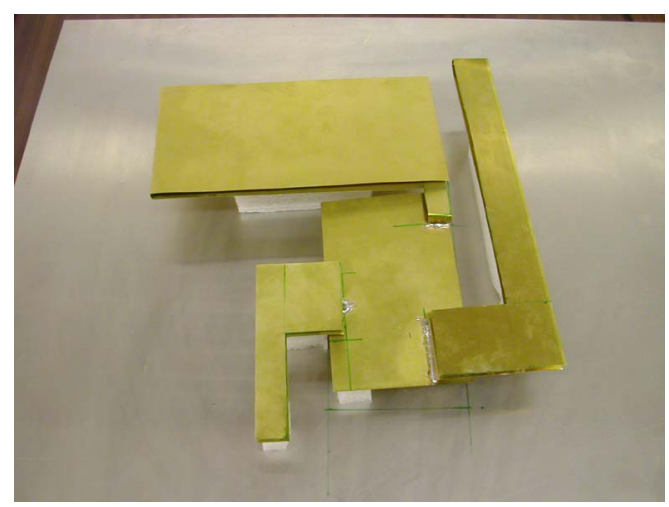

Figure 4. Achieved prototype. 
The reflection coefficient is presented in Figure 5. We can note a good comparison between theory and experiment. The antenna return loss shows that values better than $-6 \mathrm{~dB}$ are obtained on $\left|\mathrm{S}_{11}\right|$. A slight discrepancy at PMR band can be observed compared to the simulation. This frequency shift can be due to the mesh accuracy during simulation or manufacture tolerance.

The radiation patterns for simulations and measurements are presented in Figures 6-8. The realized gain has been measured in two azimuthal planes $(\varphi=$ $0^{\circ}$ and $\varphi=90^{\circ}$ ) over theta and for 3 frequencies ( $400 \mathrm{MHz}, 960 \mathrm{MHz}$ and 2170 $\mathrm{MHz}$ ). The obtained results are compared to the simulated ones. At $\mathrm{f}=960 \mathrm{MHz}$ and $\mathrm{f}=2170 \mathrm{MHz}$ the measured realized gain is still upper than $3 \mathrm{~dB}$. By cons at $400 \mathrm{MHz}$, the measured results are somewhat less satisfactory. The main reason of these differences between simulation and measurement, excepting the tolerance of the measurement base, can be explained by the difficulties for the realization of the complex antenna. It is possible to conclude that the gain satisfies the specifications.

\section{Conclusion}

A novel quad-band antenna was presented. After various parametric studies, the optimum design was obtained. Thus, the proposed antenna provides a large bandwidth at four bands. The reflection coefficient is less than $-6 \mathrm{~dB}$ over all

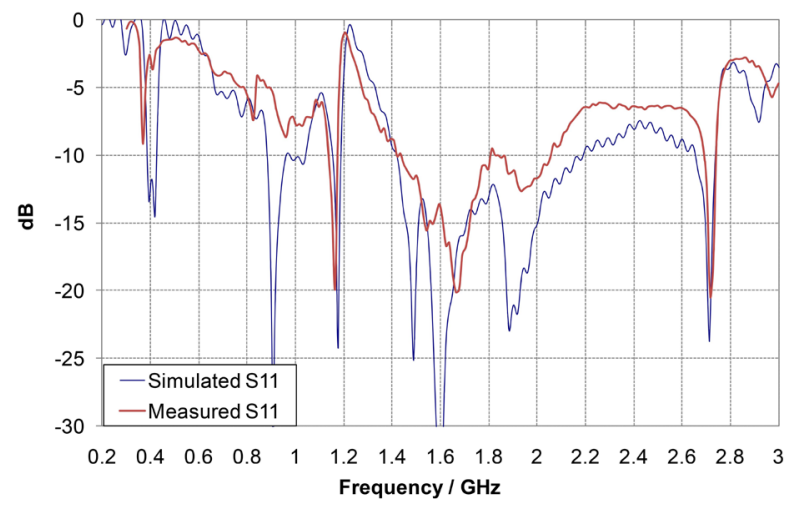

Figure 5. Simulated and measured $\mathrm{S}_{11}$.

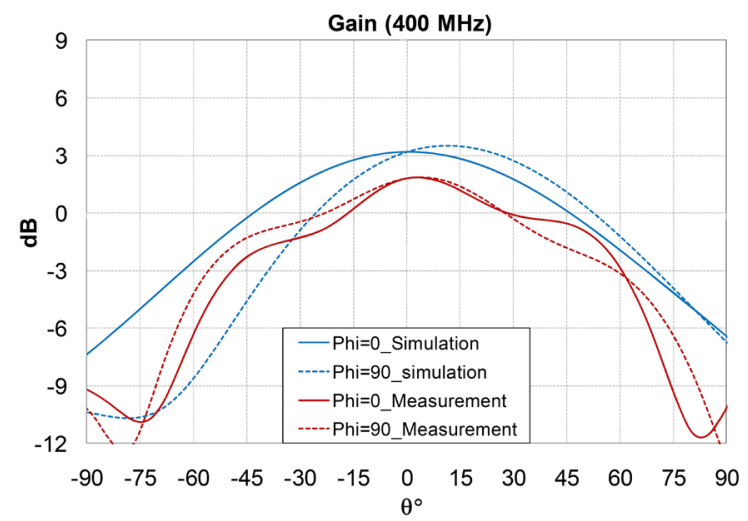

Figure 6. Simulated and measured radiation results at $\mathrm{f}=400 \mathrm{MHz}$. 


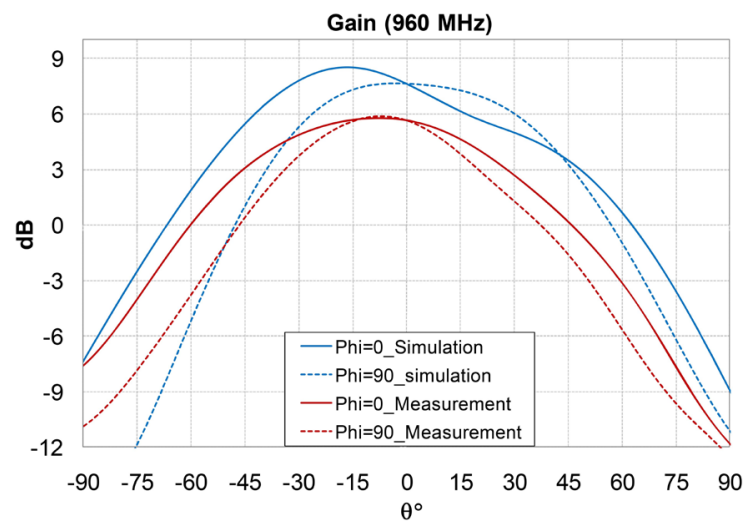

Figure 7. Simulated and measured radiation results at $\mathrm{f}=960 \mathrm{MHz}$.

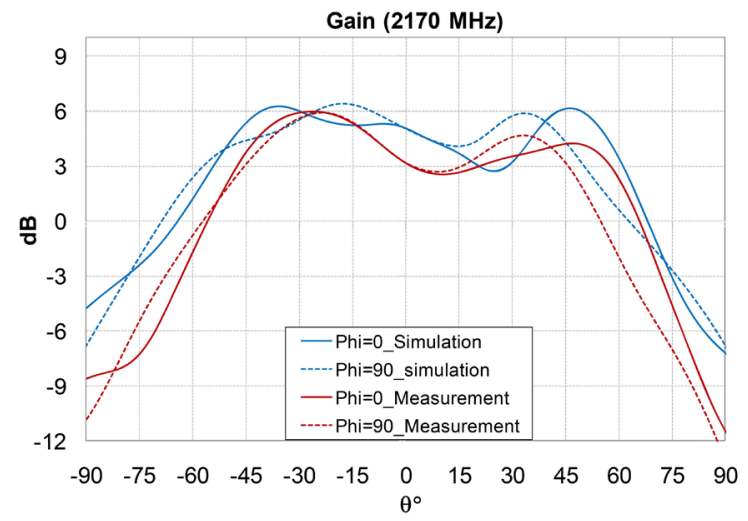

Figure 8. Simulated and measured radiation results at $\mathrm{f}=2170 \mathrm{MHz}$.

bands (PMR, GSM, DCS and UMTS). Concerning the gain, it is higher than $3 \mathrm{~dB}$ over all bands. A prototype has been manufactured and measured. The simulated results have been compared against measurements with a very good agreement at upper frequencies. Thus, the proposed antenna is a very attractive solution for Mobile communication and for cellular phone localization systems where antennas that can operate at several bands are required.

\section{Conflicts of Interest}

The authors declare no conflicts of interest regarding the publication of this paper.

\section{References}

[1] Ammann, M.J. and Chen, Z.N. (2003) Wideband Monopole Antennas for Multi-Band Wireless Systems. IEEE Antennas and Propagation Magazine, 45, 146-150. https://doi.org/10.1109/MAP.2003.1203133

[2] Agarwall, N.P., Kumar, G. and Ray, K.P. (1998) Wide-Band Planar Monopole Antennas. IEEE Transactions on Antennas and Propagation, 46, 294-295. https://doi.org/10.1109/8.660976

[3] Ray, K.P., Anob, P.V., Kapur, R. and Kumar, G. (2001) Broadband Planar Rectangular Monopole Antennas. Microwave Optical Technology Letters, 28, 55-59. 
https://doi.org/10.1002/1098-2760(20010105)28:1<55::AID-MOP16>3.0.CO;2-X

[4] Villemaud, G., Decroze, C., Dall'omo, C., Monédière, T. and Jecko, B. (2004) Dual-Band Printed Dipole Antenna Array For An Emergency Rescue System Based on Cellular-Phone Localization. Microwave Optical Technology Letters, 42, 249-253. https://doi.org/10.1002/mop.20267

[5] El Sayed Ahmad, A., Floch, J.M., Choumane, A. and Morgand, P. (2020) Design of Ellipse Antenna Array for Cellular Phone Localization Systems. Wireless Engineering and Technology, 11, 13-22. https://doi.org/10.4236/wet.2020.112002

[6] Sandler, S.S. and King, R.W.P. (1994) Compact Conical Antennas for Wideband Coverage. IEEE Transactions on Antennas and Propagation, 42, 436-439. https://doi.org/10.1109/8.280735

[7] Tung, H.C., Fang, S.T. and Wong, K.L. (2002) Printed Dual-Band Monopole Antenna for 2.4/5.2-GHz WLAN Access Point. Microwave Optical Technology Letters, 35, 286-288. https://doi.org/10.1002/mop.10585 